\title{
DEMOCRACIA: BREVE ENSAIO
}

Patrícia Garcia da Silva Carvalho ${ }^{1}$

\section{Resumo:}

Este artigo configura-se como ensaio de articulação entre as temáticas democracia, participação social e capitalismo a partir dos estudos de sociólogos, filósofos, cientistas políticos brasileiros e estrangeiros. Além de apresentar panorama da democracia no mundo com base no índice de democracia de 2017 organizado pela revista The Economist. Os critérios utilizados para composição do índice foram o processo eleitoral e pluralismo, o funcionamento do governo, a participação política, a cultura política e as liberdades civis, com notas que vão de 0 a 10. Uma análise do perfil de pontuação do Brasil, em 2017, denotou que a nossa democracia está em construção, pela diversidade de pontuação nos índices. Esses resultados foram discutidos a partir da concepção de democracia perpassando-se as democracias políticas, sociais e econômicas. Referência ao período eleitoral brasileiro, em 2018, finalizou as reflexões.

Palavras-chave: capitalismo, democracia, neoliberalismo, participação social

\begin{abstract}
This article is an essay of articulation between the themes democracy, social participation and capitalism based on the studies of sociologists, philosophers, Brazilian and foreign political scientists. In addition to presenting a panorama of democracy in the world based on the index of democracy of 2017 organized by The Economist magazine. The criteria used for composition of the index were the electoral process and pluralism, the functioning of government, political participation, political culture and civil liberties, with grades ranging from 0 to 10. An analysis of the Brazilian punctuation profile, in 2017, denoted that our democracy is under construction, for the diversity of punctuation in indexes. These results were discussed from the conception of democracy through political, social and economic democracies. Reference to the Brazilian electoral period, in 2018, finalized the reflections.
\end{abstract}

Keywords: capitalism, democracy, neoliberalism, social participation

1 IGC/UFMG (Bióloga, Mestre e Doutoranda em Geografia e Análise Ambiental) patricia.garcia.carvalho@gmail.com 


\section{APRESENTAÇÃO}

Este artigo configura-se como ensaio, primeira experiência de refletir e compartilhar ideias que articulem democracia, participação social e capitalismo. Essa oportunidade está vinculada à disciplina de Colóquios Interdisciplinares do Programa de Pós-graduação em Geografia, do Instituto de Geociências da Universidade Federal de Minas Gerais.

O doutorado trouxe a chance de me aproximar das Ciências Sociais (Sociologia, Política) e articular o campo teórico dessas ciências com as minhas observações e inquietudes no âmbito da educação e da gestão ambiental.

Ao mesmo tempo, o Brasil vivenciava uma eleição para presidência em novos modelos de campanha e com a ascensão de um candidato com perfil militar, autoritário, reacionário, conservador, e alinhado aos interesses da ultradireita. Como cidadã vivia a inquietude do momento e a busca por compreender as raízes históricas do que agora vivenciávamos.

Assim, o ensaio representa a oportunidade de refletir sobre as buscas profissionais e cidadãs. Para tal, alicercei-me nas ideias do sociólogo Francisco de Oliveira; do educador Antônio Cabral Neto; do historiador Erick Kayser; do filósofo Vladimir Safatle, das cientistas políticas Camila Vasconcelos e Simone Viscarra; do cientista político Steven Levitsky, do sociólogo Larry Diamond, dentre outros.

Os dados que retratam o panorama mundial da democracia foram retirados do índice de Democracia de 2017 (publicado em 2018), elaborado e publicado pelo The Economist que desde 2006 realiza pesquisas em mais de 100 países.

O artigo está dividido em três momentos, um resgate conceitual do termo democracia com aporte histórico, a apresentação do panorama mundial do índice de democracia e por último, articulações de ideias e autores sobre o comprometimento das democracias no Brasil e em outras regiões do globo.

Nas considerações finais além de apresentar uma síntese das ideias discutidas ao longo do texto, também inserimos, dada a sincronicidade com o processo eleitoral para presidente em fins de 2018, uma visão reflexiva sobre a democracia brasileira. 


\section{1 - INTRODUÇÃO}

O significado de democracia está vinculado à Grécia Antiga, e aos vocábulos demo, povo e kracia, autoridade, poder, governo. Em sua origem histórica a democracia ateniense configurava-se como direta, realizada na cidade, e através de assembleias, nas quais podiam participar apenas pessoas do gênero masculino, com mais de dezoito anos de idade, filhas de pais atenienses. Assim, apenas aqueles que tivessem adquirido o status de cidadão estava credenciado a usufruir plenamente dos diretos civis e políticos. (NETO, 1997, p. 288)

Nesse contexto, a democracia ateniense foi marcada pela exclusão de mulheres, estrangeiros, escravos e jovens com menos de 18 anos. Ainda no âmbito da participação nas assembleias, a frequência era mais constante de trabalhadores e negociantes da cidade e, a participação da população urbana mais rica era pouco significativa visto a resistência desse setor ao regime democrático (NETO, 1997, p.289)

Interessa ainda pontuar que apenas um número reduzido de cidadãos exercia o direito de falar na eclésia, eram os líderes que tinham credibilidade para formular a condução política, mas ter uma liderança não indicava a renúncia ao poder decisório. O corpo político ateniense era formado pela aristocracia, pela classe média rural e a população urbana, assim, conviviam artesãos, camponeses e a classes mais elevadas que tinham grau de instrução maior.

Nesse sentido, o pesquisador Antônio Cabral Neto (1997, p. 290) destaca um aspecto relevante, a democracia ateniense assegurava a igualdade política mas realizava-se em meio a desigualdade material, o que manifestava o caráter limitativo da participação política.

Ao se reportar à democracia ateniense Neto destaca ainda a existência de mecanismos que possibilitavam responsabilizar os líderes e membros perante o corpo político, assim, existia fiscalização da magistratura no âmbito particular e da vida pública, bem como, rigorosa análise da prestação de contas ao final do mandato.

Configura-se assim os alicerces da concepção de democracia que se desenvolve no seio das revoluções burguesas nos séculos XVII e XVIII na Europa baseada no ideário liberal destacando-se que a democracia dos modernos subordina a condição de cidadão à propriedade privada, restringindo dessa forma, a expressão democrática.

O pensamento liberal tem seu arcabouço nas ideias de Locke, “...qualquer sociedade política não pode existir nem subsistir sem ter em si o poder de preservar a propriedade - isto -e, 
a vida, a liberdade e os bens - contra os danos e ataques de outros homens..." (LOCKE, 1983, p.67 apud NETO, 1997, p.292).

Assim, a cidadania associada à teoria liberal está atrelada à propriedade privada, indivíduo livre e cidadão são então sinônimos mediados pela propriedade. Acrescenta-se o fato de que o sufrágio universal na Europa do século XIX era privilégio dos detentores de propriedade ou daqueles que pagavam certa quantia em impostos. (NETO, 1997, p. 293).

Nesse aspecto o pensamento liberal pode ser considerado um avanço pelo reconhecimento da igualdade individual (todos os homens são iguais perante a lei) que pese na prática a viabilização desse direito. Assim o nexo entre liberalismo e democracia baseia-se em um ponto comum: o indivíduo.

De acordo com Bobbio (1993) citado por Neto (1997, p. 295), a democracia pode ser considerada como um prolongamento do estado liberal pela sua fórmula política, a soberania popular. "Esta tornar-se-ia possível, na medida em que um maior número de cidadãos tivesse o direito de participar direta e indiretamente da tomada de decisões coletivas, significando a extensão dos direitos políticos até o limite do sufrágio universal masculino e feminino. ”

A democracia moderna em sua origem configura-se como democracia representativa e a sua marca é a representação política, na qual o representante deve estar voltado para atender aos interesses da nação e não aos interesses particulares dos representados. De acordo com Neto o processo representativo demanda mecanismos capazes de ampliar a representação e assegurar que o cidadão passe a interferir concretamente nas decisões sociais e econômicas por meio dos órgãos de decisão política (NETO, 1997, p. 296).

Quanto à democracia direta, Rousseau (1983 apud Neto, 1997, p.297) recoloca a questão da participação direta como uma necessidade histórica, pois na emergência da sociedade de massas, do capital e das lutas trabalhistas a democracia acaba por se conformar ao capitalismo liberal na medida em que a burguesia para se manter hegemônica, se vê na necessidade de fazer concessões. Assim, para Rousseau é indispensável a adoção do contratualismo como forma de legitimar as forças da sociedade e fundar a sociedade baseada na igualdade e na liberdade.

Na ótica de Rousseau, o Estado é uma comunidade politicamente organizada que tem a função soberana de exprimir a vontade geral e o governo se constitui apenas como agente executivo do Estado, não cabendo a formulação da vontade, mas apenas a tarefa de executá-la. Além disso, Rousseau destacava a importância da participação popular e o caráter educativo da 
participação, como meio de desenvolver uma ação responsável, individual, social e política como fruto do processo de participação social, chamando a atenção para o fato de que as desigualdades existentes no campo econômico não deveriam levar à desigualdade política (NETO, 1997, p.298).

De acordo com Neto (1997, p.300), a democracia direta deve ser concebida como complementar e não como alternativa à democracia representativa e avança ao propor a necessidade de sintonia entre democracia econômica, política, social e cultural. Assim, a ampliação da democracia está atrelada à redução das desigualdades sociais, não podendo se restringir a abordagem democrática apenas à forma de governo.

Neste ponto, a condição social e econômica dos atores sociais que estão vinculado ao processo democrático merece destaque. Assim, ampliar o número de eleitores e os espaços de exercício cidadão do direito ao voto passar a não ser suficiente, esse crescimento deve estar associado ao nível de vida, ao índice de educação, ao acesso inequívoco às decisões políticas e ao controle sobre seus representantes.

Algumas conquistas retratam o alargamento da dimensão política do processo democrático, tais como o sufrágio universal, a organização social em sindicatos e no terceiro setor, o pluralismo partidário, e essas por sua vez, acabaram por demandar ao Estado políticas sociais, o chamado Estado do Bem-Estar Social resultou de "uma resposta a uma demanda vinda de baixo, a uma demanda democrática no sentido pleno da palavra" (BOBBIO, 1986, p.35 apud NETO, 1997, p.302).

Assim, durante todo o período de pós-guerra o Estado Social foi celebrado como a solução política para as contradições sociais. Contudo, é importante frisar que o caráter de classe do Estado persiste, pois, ao determinar um padrão de financiamento o Estado assegura o status quo da sociedade de classes reproduzindo-se o modelo de sociedade baseado na desigualdade e na exploração. Essa concepção de Estado e de jogo democrático passou a se deparar com problemas e as contradições do modelo intensificaram-se a partir da década de 70 .

Neto cita Habermas ao analisar os problemas associados ao Estado do Bem-Estar aponta que o a tensão entre a economia capitalista e a política democrática traduz-se na desconfiança das classes trabalhadoras em ascensão que abandonaram os ideais coletivistas e, do outro lado, aqueles que apesar de reconhecerem as conquistas sociais, conscientizam-se da contradição interna entre o método do Estado do bem-Estar Social e seus objetivos (NETO, 1997, p.304). Cabe ressaltar que a condição de cidadania que serviu de base para a edificação do tipo clássico 
de Welfare manteve-se viável até o momento em que o processo de acumulação financiou certo nível de bem-estar, sem ameaçar as taxas de lucro.

A crise assim delineada a partir de década de 70 evidencia a existência de um sistema social em que parcela dos cidadãos têm condições de vida precárias e têm seus direitos assegurados apenas no nível formal, comprometendo-se progressivamente a democracia política e as democracias social, econômica e cultural. É importante frisar que sob a égide do neoliberalismo é possível constatar a redução na amplitude das políticas sociais. Neto refere-se assim, ao deslocamento do eixo da cidadania, “...do atendimento amplo às necessidades básicas do cidadão para o atendimento mínimo com participação dos clientes sob a custódia direta ou indireta do Estado" (NETO, 1997, p.306).

O autor aponta ainda que a dimensão econômica da democracia adstrita às divisas do capitalismo deve se coadunar com à lógica que rege a organização desse modelo de sociedade, no qual a redistribuição de renda não deve ameaçar a propriedade privada dos meios de produção, nem eliminar a diferenciação de classe, e comprometer as taxas de lucro.

Nesse contexto, Neto explica algumas características do processo democrático brasileiro: construção social com quase ou nenhuma tradição democrática; conservadorismo entranhado no aparelho de Estado e na sociedade civil, dificuldade de participação política mais ampla da sociedade em função das regras do jogo democrático serem definidas e postas pelas elites a partir dos interesses particulares dessas, limitação do acesso aos bens materiais e culturais socialmente produzidos pela ampla maioria da população e, o autoritarismo que ainda se expressa em nossa sociedade.

Esse cenário corrobora as contradições brasileiras, pois apesar do aumento no número de eleitores, a ampliação das esferas de participação política da sociedade civil organizada, o crescimento econômico no país não foi acompanhado da implantação de programas sociais capazes de modificar o quadro social até o século XXI com o governo petista.

O padrão de financiamento executado pelo Estado tem favorecido ao capital em detrimento do trabalho, de forma mais ostensiva que nos países europeus e associado a isso, uma prática social seletiva e assistencialista agravada pela corrupção. Diante desse cenário falar em Estado de Bem-Estar Social fica descontextualizado, poder-se-ia falar mais em "mal-estar" (Neto, 1997, p. 309) do que bem-estar para profusos setores da sociedade. 
Dessa forma parece factual dizer que as desigualdades econômicas funcionem como obstáculos à democracia, pois o acesso e ampliação das dimensões política e culturais da democracia estão inexoravelmente associadas às possibilidades sociais do cidadão participar do jogo democrático.

Ao mesmo tempo, ao se analisar o processo de construção da sociedade brasileira pode-se averiguar que carregamos uma forte herança da escravidão, e também uma burguesia que não se defrontou e não vivenciou a negociação com a contraparte de classe concebendo-se assim, a dificuldade em reconhecer e institucionalizar a diversidade dos outros, seja no campo político, social, cultural e econômico (NETO, 1997, p. 310).

Oliveira (2003) pontua que a independência brasileira foi atrelada a uma monarquia conservadora que rompeu a Constituição de 1924 e que a abolição não resolveu a questão do negro no Brasil e que a questão permanece não resolvida nos dias atuais. E continua, os movimentos simultâneos do abolicionismo e do republicanismo instauraram a República, mas essa tutelada pelo poder militar (OLIVEIRA, 2003, p.28).

Ainda, segundo Oliveira, “... dos anos 30 aos anos 90, foram 35 anos de ditadura e uma tentativa de golpe a cada três anos no Brasil...", a " panela de pressão" do processo de modernização forçava o sistema político, e mesmo, a ditadura se quebrou, usando golpes dentro de golpes (OLIVEIRA, 2003, p.33). E o governo de Fernando Henrique Cardoso (FHC) teve a capacidade de unir forças sociais e políticas numa coalização e fazê-la trabalhar politicamente, a partir das reformas constitucionais.

Contudo, FHC ao desregulamentar e promover a desregulação do controle público, e ao implantar as privatizações mudou o controle do capital no Brasil alterando em grande parte o caráter da base material da propriedade, levando a que as imbricadas relações e mecanismo de interação entre economia e política, pulverizassem a coalização.

Esse processo culmina com a candidatura de Luís Inácio da Silva, fruto de uma longa acumulação histórica desde os anos 70 e resultado de um conjunto de forças pulverizadas. Oliveira ao analisar essa trajetória histórica pergunta, se chegamos a um estágio de maturidade democrática que nos dispensa de uma maior atenção com relação ao jogo democrático na nossa economia neoliberal e pontua que a disputa no campo político/econômico está fortemente desbalanceada, desequilibrada. E responde ser necessário voltar a interrogar-nos, pois o fortalecimento da vontade democrática entra em contraste com o enrijecimento das instituições e o voto cidadão, apesar de ser exercido, não decide nada. 
O voto não interfere ou decide sobre as agências que administram o petróleo, as telecomunicações, a vigilância sanitária, a autonomia do Banco Central, ou os transportes. E o pesquisador avança no sentido de delinear o papel das eleições e do voto, esse nos interessa porque "estamos dentro da institucionalidade capitalista e burocratizada que anula a política" (p.42). E a política no sistema capitalista é a única via pela qual podemos controlar o mercado, dado que a propriedade é privada. Assim, no sistema econômico e de organização social neoliberal e capitalista é necessário controlar as instituições.

Oliveira finaliza a palestra ${ }^{2}$ afirmando que o "processo eleitoral está sendo no sentido de retirar o alcance do voto popular das decisões mais cruciais a respeito da economia, da sociedade e da vida cotidiana" (OLIVEIRA, 2003, p.43).

Podemos nos perguntar o quanto a democracia liberal contemporânea está reduzida a procedimentos, rotação de poderes, partidos políticos. A sociedade plural tem no jogo democrático a garantia do pleno exercício de direitos das minorias, a democracia é essencial para a construção e conservação de direitos. E essa é uma das contradições internas da articulação entre democracia política e o capitalismo neoliberal ${ }^{3}$.

A distopia neolioberal caracterizada por operar por exclusão, por lutas e guerras, pela exacerbação da competição, pelo culto ao efêmero e descartável, pela redução do sujeito a mero consumidor, pela fragmentação e dispersão do trabalho, pelas organizações supra nacionais, pela transformação do direito em mercadoria, pelo deslocamento do espaço público para o privado e valorização desse último compromete em suas bases o resgate social, cultural e político das minorias e dos pobres, comprometendo-se assim, o exercício democrático e a cidadania.

De acordo com Therborn (1995, p.39), “o neoliberalismo é uma superestrutura ideológica e política que acompanha uma transformação histórica do capitalismo moderno". Essas mudanças envolvem a diluição do poder de classe dos sindicatos e estados de bem-estar redistributivos, e segundo, Kayser (2018), também, o comprometimento das expectativas associadas às democracias liberais.

\footnotetext{
${ }^{2}$ Francisco de Oliveira, A Sociologia Política e a Democracia no Brasil, conferência proferida em 25/04/2003 no auditório da Reitoria da Universidade Federal de Santa Catarina.

${ }^{3}$ Para Bourdieu (1998, p.3), “...o programa neoliberal tende globalmente a favorecer a ruptura entre a economia e as realidades sociais, configurando-se como um programa de destruição metódica do coletivo, de todas as estruturas coletivas capazes de interpor obstáculo à lógica do mercado puro”.
} 
Ao citar Dartot \& Laval (2016), Kayser indica que o neoliberalismo se configura hoje, como a razão do capitalismo contemporâneo, como racionalidade capaz de não só estruturar a ação dos governantes, mas também a conduta dos governados. Assim, direcionando políticas públicas, relações econômicas e remodelando a subjetividade e a sociedade, na qual o indivíduo passa a ser concebido como empresa e a individualização das relações sociais e a erosão das solidariedades coletivas são fatos.

Nesse contexto, essa noção de indivíduo e o rompimento da coesão social alicerçada em mecanismo coletivos contribui para a fragilização dos sistemas democráticos. Mas Kayser (2018, p. 6) torna ainda mais complexa a análise, ao propor que "o neoliberalismo não deve ser interpretado apenas como política econômica ou ideologia, ou a combinação destas mas somo como nova forma de racionalidade ou hegemonia" capaz de alterar a temporalidade contemporânea, desenvolvendo o presentismo ${ }^{4}$, ou seja, experenciar a relação temporal como um presente único e perpétuo, o instante estagnado, um presente onipotente que valoriza só o imediatismo.

Essa noção é importante e dialoga com análises de filósofos contemporâneos tais como Lypovetsky, Freitas/Baudrillard e, Zizek que apontam para uma aceleração da percepção temporal nas sociedades contemporâneas levando ao consumismo massificado, ao imediatismo das vivências consubstanciadas em desejos efêmeros.

Kayser faz uma ressalva que consideramos importante frisar, "o presentismo não é um fruto planejado do neoliberalismo, mas sem a presença hegemônica de suas ideias, é difícil imaginar o regime de historicidade, pelo menos na forma com que se manifesta" (KAYSER, 2018, p.7). E o historiador avança no seu raciocínio chamando a atenção para o fato de que a experiência presentista expõe uma dualidade social (antagônica), a felicidade do consumo, das classes sociais privilegiadas e a ascensão social que geram um presente eterno; e no outro sentido, “a classe trabalhadora empobrecida, os novos precariados, imigrantes e os demais excluídos, na luta pela sobrevivência, que têm o presente como âncora no real, e o presente surge como resposta a um futuro negado e a um passado quase esquecido”. Em ambos os casos se vislumbra a sensação de urgência motivada pela aceleração do tempo.

Assim, o comprometimento da esfera do coletivo, a valorização do individualismo, associados ao presentismo, corroboram para que "futuros idealizados através da ação coletiva

${ }^{4}$ Noção desenvolvida por Hartog, 2015. 
sedam lugar a um horizonte de expectativas reduzido, onde os sonhos futuros restringem-se a desejos individuais".

O historiador propõe ainda uma articulação entre presentismo e representação distópica do futuro marcada pela sensação de que estaríamos vivendo no fim dos tempos ${ }^{5}$ Tempos de crises que ameaçam a vida social, que promovem a dissolução das relações sociais ampliando assim, o espectro da adesão subjetiva produzida perlo medo ${ }^{6}$.

O medo é hoje um afeto que perpassa as sociedades ocidentais, medo da violência urbana, medo da onda reacionária às minorias, medo de perder a condição social e econômica, medo do rompimento das estruturas democráticas, medo das crises econômicas que abalam o sistema político e social no mundo, etc. Essa temática voltará a ser abordada no transcorrer do texto.

Buscamos até aqui, apresentar uma breve evolução histórica da concepção de democracia e articulações possíveis com a estrutura político, social e econômica da sociedade contemporânea ocidental, sobretudo.

$\mathrm{Na}$ sequência passamos a discorrer sobre o panorama da democracia no mundo e a refletir sobre a situação brasileira. Os dados que substanciam as reflexões foram produzidos pelo The Economist.

\section{2 - PANORAMA MUNDIAL E BRASILEIRO}

Dados internacionais que avaliam a instauração de regimes políticos no mundo indicam que o número de democracias aumentou durante as últimas décadas do século XX, sobretudo, na América Latina e no continente africano. Mas esse movimento estagnou após os anos 2000 (Freddom House, 2012 e Polity IV Project, 2010 e EIU, 2013).

Para a nossa análise tomamos como substrato para a apresentação do panorama da democracia no mundo, o estudo da revista The Economist, o The Economist Intelligence Unit (The EIU) faz parte do Economist Group que faz previsões econômicas, políticas e sociodemográficas e

\footnotetext{
${ }^{5}$ Kayser cita Zizek (2011, p.11-12), os quatro cavaleiros do Apocalipse que poderiam levar o sistema capitalista global a um ponto zero: a crise ecológica, as consequências da revolução biogenética, os desequilíbrios do próprio sistema e o crescimento explosivo das divisões e exclusões sociais.

${ }^{6} \mathrm{O}$ medo como afeto político será tratado mais adiante a partir do Circuito dos Afetos de Vladimir Safatle.
} 
presta consultoria através de pesquisas, com cenários econômicos e análise de riscos nos diferentes países.

O índice de Democracia foi criado pela The EIU, em 2006, e é atualizado anualmente desde 2010, apresentando um retrato da situação da democracia em 165 países independentes e em 2 territórios. As cinco categorias democráticas são: processo eleitoral e pluralismo, liberdades civis, funcionamento do governo, participação política e cultura política. Cerca de 60 indicadores compõem a pontuação final que varia de 0 a 10 para cada país. Delineando-se assim, uma escala de pontuação na qual, de 0 a 4 estão inseridos os países com regimes autoritários, de 4 a 6 com regimes híbridos, de 6 a 8 com democracias imperfeitas, e de 8 a 10 países com democracias plenas.

Segundo a pesquisa do EIU (2018, p.66) as categorias democráticas são assim definidas:

Democracias plenas são nações onde as liberdades civis e as liberdades políticas básicas não são apenas respeitadas, mas também reforçadas por uma cultura política conducente à prosperidade dos princípios democráticos. Democracias imperfeitas apresentam falhas e caracterizam nações onde as eleições são justas e livres e as liberdades civis básicas são honradas. Essas nações têm falhas significativas em outros aspectos democráticos, incluindo cultura política subdesenvolvida, baixos níveis de participação na política e questões no funcionamento da governança. Regimes híbridos configuram nações onde existem irregularidades consequentes nas eleições, impedindo-as de serem justas e livres. Esses países geralmente têm governos que pressionam opositores políticos, judiciários não independentes e têm corrupção generalizada, assédio e pressão sobre a mídia, estado de direito. E regimes autoritários nos quais o pluralismo político desapareceu ou é extremamente limitado. Essas nações são muitas vezes monarquias absolutas ou ditaduras, podendo existir algumas instituições convencionais de democracia, mas com significado escasso. Infrações e abusos de liberdades civis são comuns, eleições (se acontecerem) não são justas e livres, a mídia é muitas vezes estatal ou controlada por grupos associados com o regime dominante, o judiciário não é independente, e eles são caracterizados pela presença de censura onipresente e supressão de crítica governamental.

A tabela 1 apresenta os resultados por regiões do mundo a partir dos dados de 2017/2018, do EIU.

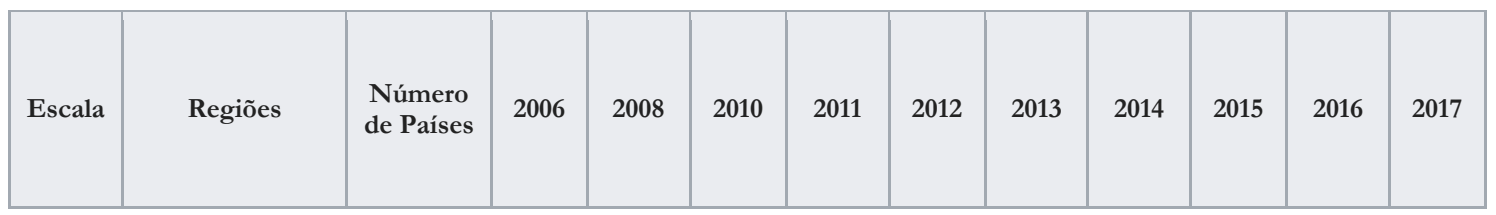




\begin{tabular}{|c|c|c|c|c|c|c|c|c|c|c|c|c|}
\hline 1 & $\begin{array}{l}\text { América do } \\
\text { Norte }\end{array}$ & 2 & 8.64 & 8.64 & 8.63 & 8.59 & 8.59 & 8.59 & 8.59 & 8.56 & 8.56 & 8.56 \\
\hline 2 & $\begin{array}{l}\text { Europa } \\
\text { Ocidental }\end{array}$ & 21 & 8.60 & 8.61 & 8.45 & 8.40 & 8.44 & 8.41 & 8.41 & 8.42 & 8.40 & 8.38 \\
\hline 3 & $\begin{array}{l}\text { América Latina e } \\
\text { Caribe }\end{array}$ & 24 & 6.37 & 6.43 & 6.37 & 6.35 & 6.36 & 6.38 & 6.36 & 6.37 & 6.33 & 6.26 \\
\hline 4 & Ásia e Austrália & 28 & 5.44 & 5.58 & 5.53 & 5.51 & 5.56 & 5.61 & 5.70 & 5.74 & 5.74 & 5.63 \\
\hline 5 & $\begin{array}{l}\text { Europa Central e } \\
\text { Oriental }\end{array}$ & 28 & 5.76 & 5.67 & 5.55 & 5.50 & 5.51 & 5.53 & 5.58 & 5.55 & 5.43 & 5.40 \\
\hline 6 & $\begin{array}{l}\text { África } \\
\text { Subsaariana }\end{array}$ & 44 & 4.24 & 4.28 & 4.23 & 4.32 & 4.33 & 4.36 & 4.34 & 4.38 & 4.37 & 4.35 \\
\hline 7 & $\begin{array}{l}\text { Oriente Médio e } \\
\text { Norte da África }\end{array}$ & 20 & 3.54 & 3.48 & 3.52 & 3.62 & 3.73 & 3.68 & 3.65 & 3.58 & 3.56 & 3.54 \\
\hline & Mundo & 167 & 5.52 & 5.55 & 5.46 & 5.49 & 5.52 & 5.53 & 5.55 & 5.55 & 5.52 & 5.48 \\
\hline
\end{tabular}

Tabela 1 - Classificação das regiões do mundo pelo Índice de Democracia do EIU, 2018

Interessante observar que ao longo dos anos da pesquisa, de 2006 a 2017, a América do Norte e Europa Ocidental mantiveram-se na escala de Democracias Plenas, contudo com índices decrescentes. O decréscimo nos índices também pode ser verificado na América Latina e Caribe, na Europa Central e Oriental, mantendo-se, contudo, a escala em regimes de democracias imperfeitas e regimes híbridos respectivamente.

$\mathrm{Na}$ região composta pela Ásia e Austrália pode-se verificar flutuação e queda de pontuação em 2017, da mesma forma que a África Subsaariana, com queda a partir de 2015, e o Oriente Médio e Norte da África com pontuações decrescentes a partir de 2012. A tabela 2 apresenta os tipos de regime, número de países e população.

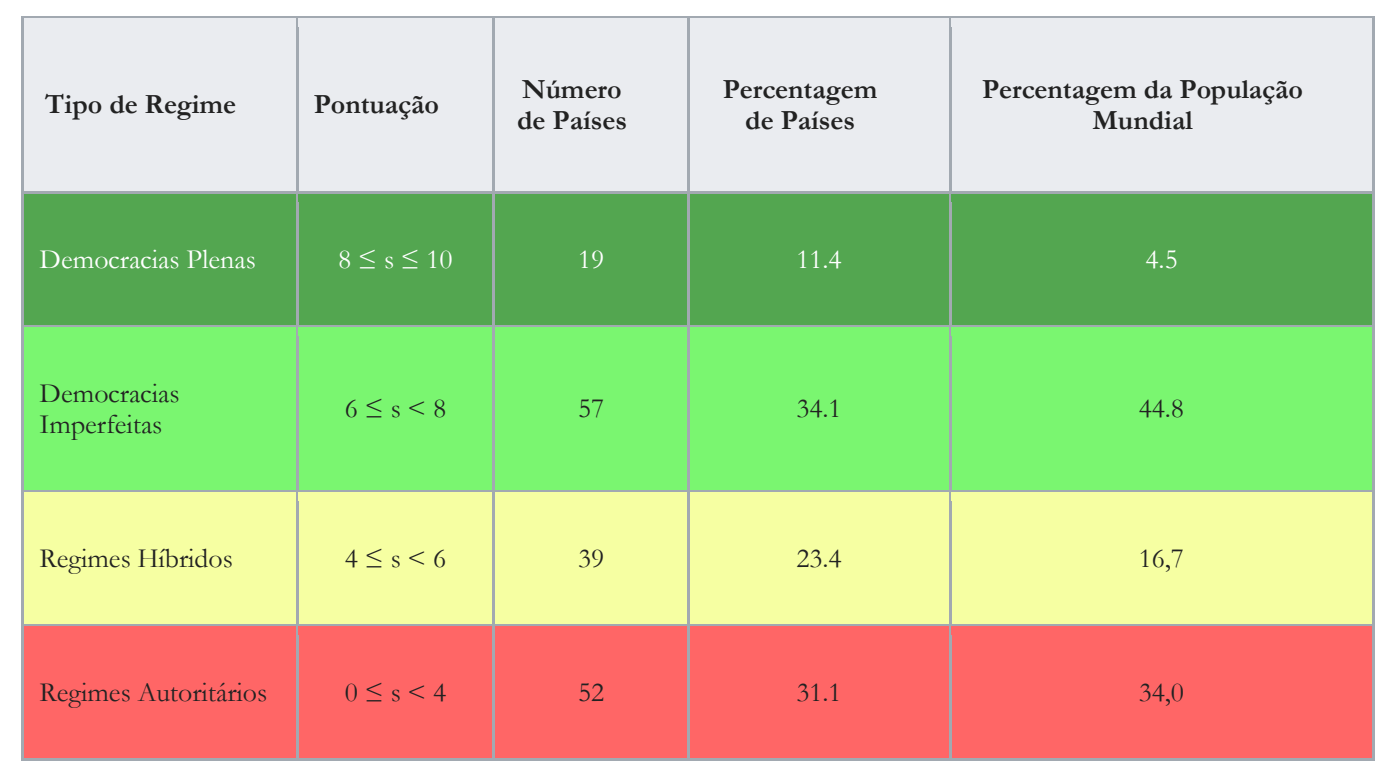

Tabela 2 - Tipo de regime, número de países e população. Fonte: EIU, 2018. 
Observação: A população mundial envolve a soma dos 167 países envolvidos no estudo. A pesquisa incluiu quase todas as nações soberanas e excluiu apenas alguns países muito pequenos (Mônaco, Andorra, Cidade do Vaticano, etc.), e a soma é praticamente equivalente à população mundial estimada em meados de 2017. Salientou-se no estudo que os territórios dependentes não foram separados dos países que os administram, embora muitos deles tenham um alto grau de autogoverno e organizações políticas independentes.

$\mathrm{Na}$ tabela 2 verifica-se que a maior parte dos países e da população mundial está vinculada às democracias imperfeitas, seguida dos regimes autoritários, dos regimes híbridos e que a menor percentagem dos países está associada às democracias plenas, englobando apenas 4,4\% da população mundial.

A Figura 1, a seguir representa os países e suas respectivas escalas democráticas.

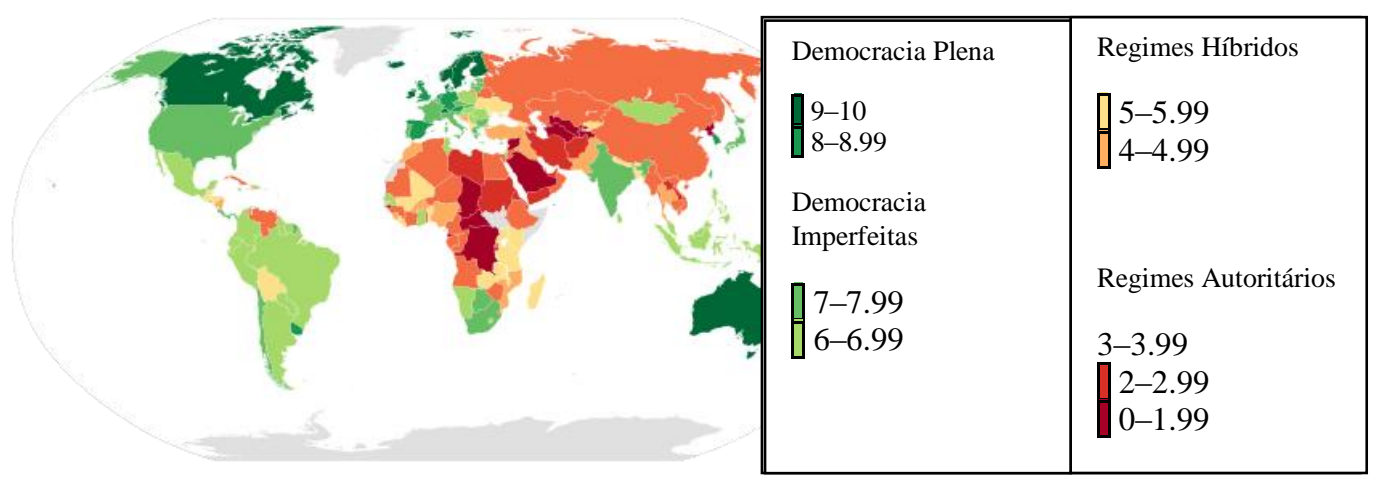

Figura 1 - Mapa do índice de democracia, 2017/2018 com base no The Economist Intelligence Unit Democracy Index, 2018

Na América do Norte, América do Sul e Europa Ocidental predominam as democracias, já nos continentes africano e asiático predominam os regimes (híbridos ou autoritários). Cabe ressaltar que a média global do índice de democracia no mundo diminuiu de 2016 para 2017, configurando a pior pontuação desde 2006. Em 2017, 89 países perderam pontuação e 27 países tiveram melhorias. Apenas 19 países foram categorizados como democracias plenas e quase todos os países são europeus, com exceção do Uruguai, do Canadá, Ilhas Maurício e da Nova Zelândia.

A Noruega ocupa o primeiro lugar com pontuação de 9,87 e os parâmetros que contribuíram para a pontuação abaixo de 10,0 foram o funcionamento do governo $(9,64)$ e as liberdades civis $(9,71)$. Entre os 10 países de democracias plenas as variáveis que rebaixaram as notas foram predominantemente o funcionamento do governo e a participação política. 
No relatório da EIU, 57 países foram enquadrados em democracias imperfeitas perfazendo 44,8\% da população mundial, figuram ente esses países os Estados Unidos, França, Alemanha, Espanha, Portugal, Reino Unido, Coréia do Sul, África do Sul, México, Índia, dentre outros.

Na América Latina, o Brasil é uma democracia imperfeita, com uma pontuação de 6,86, aproximando-se bastante de um regime híbrido. A única pontuação acima de 9,0 refere-se ao processo eleitoral e pluralismo, os menores índices estão associados à cultura política $(5,00)$ e funcionamento do governo (5,36). Nicarágua, Honduras, Guatemala, Bolívia e Haiti foram categorizados como regimes híbridos e próximos a se enquadrarem como regimes autoritários, tais como Venezuela e Cuba. (Ver tabela 3).

América Latina e Caribe 2017

\begin{tabular}{|c|c|c|c|c|c|c|c|c|c|}
\hline & $\begin{array}{c}\text { Pontuação } \\
\text { Geral }\end{array}$ & $\begin{array}{l}\text { Rank } \\
\text { Global }\end{array}$ & $\begin{array}{r}\text { Regional } \\
\text { Rank }\end{array}$ & $\begin{array}{l}\text { I Processo eleitoral } \\
\text { e pluralismo }\end{array}$ & $\begin{array}{l}\text { II Funcionamento do } \\
\text { governo }\end{array}$ & $\begin{array}{l}\text { III Participação } \\
\text { política }\end{array}$ & $\begin{array}{l}\text { IV Cultura } \\
\text { política }\end{array}$ & $\begin{array}{c}\mathrm{V} \\
\text { Liberdades } \\
\text { civis }\end{array}$ & Tipo de regime \\
\hline Uruguai & 8.12 & 18 & 1 & 10.00 & 8.93 & 4.44 & 7.50 & 9.71 & Democracia Plena \\
\hline Costa Rica & 7.88 & $=23$ & 2 & 9.58 & 7.14 & 6.67 & 6.88 & 9.12 & $\begin{array}{c}\text { Democracia } \\
\text { imperfeita }\end{array}$ \\
\hline Chile & 7.84 & $=26$ & 3 & 9.58 & 8.57 & 4.44 & 7.50 & 9.12 & Democracia imperfeita \\
\hline Jamaica & 7.29 & $=38$ & 4 & 9.17 & 7.14 & 4.44 & 6.88 & 8.82 & Democracia imperfeita \\
\hline Panamá & 7.08 & 45 & 5 & 9.58 & 6.79 & 6.11 & 5.00 & 7.94 & Democracia imperfeita \\
\hline $\begin{array}{l}\text { Trinidad e } \\
\text { Tobago }\end{array}$ & 7.04 & 46 & 6 & 9.58 & 7.14 & 5.56 & 5.00 & 7.94 & Democracia imperfeita \\
\hline Argentina & 6.96 & 48 & 7 & 9.17 & 5.00 & 6.11 & 6.88 & 7.65 & Democracia imperfeita \\
\hline Brasil & 6.86 & 49 & 8 & 9.58 & 5.36 & 6.11 & 5.00 & 8.24 & Democracia imperfeita \\
\hline Suriname & 6.76 & 50 & 9 & 9.17 & 6.43 & 5.56 & 5.00 & 7.65 & Democracia imperfeita \\
\hline Colômbia & 6.67 & $=53$ & 10 & 9.17 & 6.79 & 4.44 & 5.00 & 7.94 & Democracia imperfeita \\
\hline $\begin{array}{c}\text { República } \\
\text { Dominicana }\end{array}$ & 6.66 & 55 & 11 & 9.17 & 5.36 & 6.11 & 5.63 & 7.06 & Democracia imperfeita \\
\hline Peru & 6.49 & 61 & 12 & 9.17 & 5.36 & 5.56 & 5.00 & 7.35 & Democracia imperfeita \\
\hline Guiana & 6.46 & 63 & 13 & 8.75 & 5.71 & 6.11 & 4.38 & 7.35 & Democracia imperfeita \\
\hline El Salvador & 6.43 & 65 & 14 & 9.17 & 5.36 & 5.56 & 5.00 & 7.06 & Democracia imperfeita \\
\hline México & 6.41 & $=66$ & 15 & 7.83 & 6.43 & 7.22 & 4.38 & 6.18 & Democracia imperfeita \\
\hline Paraguai & 6.31 & $=71$ & 16 & 8.75 & 6.07 & 5.00 & 4.38 & 7.35 & Democracia imperfeita \\
\hline Equador & 6.02 & 76 & 17 & 8.75 & 4.64 & 5.56 & 4.38 & 6.76 & Democracia imperfeita \\
\hline Guatemala & 5.86 & 80 & 18 & 7.92 & 5.71 & 3.89 & 5.00 & 6.76 & Regime híbrido \\
\hline Honduras & 5.72 & 82 & 19 & 8.25 & 5.36 & 4.44 & 4.38 & 6.18 & Regime híbrido \\
\hline Bolívia & 5.49 & $=89$ & 20 & 7.00 & 4.64 & 5.00 & 3.75 & 7.06 & Regime híbrido \\
\hline Nicarágua & 4.66 & $=105$ & 21 & 3.42 & 3.29 & 3.89 & 5.63 & 7.06 & Regime híbrido \\
\hline
\end{tabular}




\begin{tabular}{|cccccccccccc}
\hline Haiti & 4.03 & 114 & 22 & 5.17 & 2.21 & 2.22 & 4.38 & 6.18 & Regime híbrido \\
\hline Venezuela & 3.87 & $=117$ & 23 & 2.17 & 2.86 & 6.11 & 4.38 & 3.82 & Regime autoritário \\
\hline Cuba & 3.31 & 131 & 24 & 1.33 & 4.29 & 3.89 & 4.38 & 2.65 & Regime autoritário \\
\hline
\end{tabular}

Tabela 3 - América Latina e Caribe - pontuação e tipo de regime. Fonte: The Economist Intelligence Unit, 2018.

Uma análise do perfil de pontuação do Brasil, em 2017, denota que a nossa democracia está em construção, pela diversidade de pontuação nos índices. Sendo que, as notas do Brasil de 9,58, no critério pontuação eleitoral e pluralismo foi semelhante à de países classificados como "democracias plenas", como Suécia, Canadá, Áustria e Alemanha. No critério "funcionamento do governo", o Brasil foi classificado com a nota 5,36, igual à Grécia, o 38. colocada. Nosso país teve ainda notas muito ruins em critérios que dependem diretamente da sociedade civil, em "participação política" foi 6,11, igual a de países como Sérvia, Malásia e Moldávia. E por último, em "cultura política" o índice do Brasil foi de 5,00 menor que o de países com "regimes autoritários", tais como Myanmar, Camboja e Etiópia.

O Uruguai é o único país com pontuação final acima de 8,0. Nos países classificados como democracias imperfeitas as variáveis que comprometem a democracia são, sobretudo, a cultura política e a participação política.

Salienta-se que a média da América Latina caiu de 6,33 em 2016 para 6,26 em 2017, mas ainda assim, pontua bem acima da média global para o processo eleitoral e o pluralismo, o que não ocorre nos outros parâmetrosm visto que funcionamento do governo, bem como participação política pontuam minimamante acima da média global. O relatório indica que esse cenário reflete os problemas da região com corrupção, crime organizado, alta taxa de homicídios relacionados ao tráfico de drogas e baixos níveis de envolvimento político.

A variável cultura política fica abaixo da média global refletindo assim, baixos níveis de confiança popular na democracia. Nesse ponto o relatório cita o Latinobarómetro, um instituto chileno que publica avaliações anuais da percepção pública da democracia em oito países latinoamericanos, que demonstrou o declínio do apoio público à democracia desde o início das pesquisas em 1995, caindo para 53\% em 2017.

Cabe destacar que autores sociólogos e cientistas políticos associam a cultura política aos fatores subentendidos que influenciam na construção de sistemas políticos, tais como, atitudes, crenças, aptidões e valores comuns ao grupo. E a politização do indivíduo mantém o sistema a partir do compartilhar de expectativas comuns entre as pessoas de determinada sociedade.

Importante ressaltar que o Equador passou de um regime híbrido para democracia imperfeita, e segundo o EIU, essa mudança reflete os esforços do presidente, Lenín Moreno, para 
combater a corrupção e as limitações à liberdade de imprensa. Em contraposição, a Venezuela, passou de um regime híbrido para um regime autoritário, o que foi reconhecido pelo The Economist como um contínuo movimento da Venezuela em direção à ditadura, na medida em que o governo prendeu ou marginalizou políticos da oposição e reprimiu violentamente os protestos da oposição.

Viscarra e Casconcelos (2016) destacam que “... a evolução normativa das democracias latinas não é acompanhada pelo crescimento de uma dimensão cultural de apoio, ou seja, a região carece de uma cultura política cidadã de apoio ao sistema democrático” (2016, p. 26).

As autoras discorrem ainda sobre a América Latina e concluem que a democracia latinamericana é marcada por exagerada ênfase em procedimentos democráticos, o que faz que aspectos culturais sejam minimizados. Assim, existe um processo dicotômico vigente, no qual as democracias estão instauradas, mas com situações de instabilidade visíveis indicando que apenas os paradigmas institucionais não são suficientes para estabelecer e manter as democracias.

Na categoria de regimes autoritários estão Rússia, China, Zimbábue, Coréia do Norte e, mais 48 países que perfazem 31,1\% da população mundial. John Hoey, editora do relatório, ressaltou que o pilar democrático mais ameaçado é a liberdade de expressão, pois difamação, prevenção ao terrorismo, blasfêmia e leis estão sendo criadas para limitar as liberdades de opinião e expressão de ideais. A editora acrescenta ainda que grupos criminosos e interesses pessoais têm usado de ameaças, violência, assassinatos para suprimir a liberdade de expressão.

O documento apresenta ainda o desapontamento com o atual momento da democracia mundial denotado pelo declínio registrado nas liberdades de imprensa e chama a atenção para uma recessão democrática citando nesse ponto, Larry Diamond que analisa ser a estagnação, ou a regressão dos índices de democracia observados desde 2006, o reflexo do enfraquecimento dos governos, do afastamento das elites políticas do eleitorado, da diminuição da participação popular na política e nas eleições, e do declínio da confiança nas instituições.

Os editores do relatório ressaltam ainda a existência de um paradoxo ente o descontentamento com o funcionamento e forma do sistema de representação política e o alto nível de apoio popular às democracias. Nesse ponto do documento, é apontada a revolta popular contra o populismo e os partidos tradicionalmente de poder e as elites (nos países europeus e nos Estados Unidos) a partir dos exemplos do Brexit (saída do Reino Unido da União Europeia) e o clamor para afastar Donald Trump, nos Estados Unidos. 
O relatório destaca a questão da liberdade de expressão correlacionando a internet, mídias sociais e os limites à expressão. As maravilhas da internet e das mídias sociais significam que, em muitos aspectos, estamos vivendo "em uma época de ouro para a liberdade de expressão".

No entanto, apesar da enorme expansão das possibilidades de liberdade de expressão, na prática, a liberdade de expressão é cada vez mais restrita. De acordo com nosso ranking de liberdade de mídia, em 2017, menos da metade da população mundial tinha acesso a uma mídia livre ou parcialmente livre e desfrutava do direito de falar livremente. Além disso, em muitos desses países, a liberdade de imprensa e a liberdade de expressão estavam sendo corroídas. “A censura não é mais a prerrogativa dos regimes autoritários; está sendo implantado cada vez mais nas democracias do mundo também" (EIU, 2018, p.2).

Ainda neste âmbito, o relatório apresenta o Índice de Liberdade de Mídia, apenas 30 dos 167 países cobertos pelo Índice de Democracia, ou seja, 11\% da população mundial - são classificados como totalmente livres. E aproximadamente 97 países são classificados como nãolivres ou em grande parte não-livres indicando que mais de metade da população mundial não tem acesso a mídia livre ou parcialmente livre sendo impedida de exercer a liberdade de expressão.

Nota-se que em muitos países o Estado vem desempanhando papel significatico na redução da liberdade da mídia e da expressão. Em países democráticos e autoritários, os governos vêm instituindo leis de difamação, prevenção de leis de terrorismo, blasfêmia e leis de "discurso de ódio" para restringir a liberdade de expressão e impedir a liberdade de imprensa, somando-se a esse fato a ocorrência de intimidação, ameaças e assassinato por grupos específicos.

O conservadorismo e retrocessos na liberdade de expressão envolvem também aqueles que reivindicam o direito de não se sentirem ameaçados/ofendidos, criando dinãmica crescente de apelos por espaços seguros, proibição de tablóides, proibição de jornais e o policiamento da internet para limpar os conteúdos identificados como ofensivos.

Os editores finalizam chamando a atenção para o fato de não existir um consenso sobre como medir a democracia e esclarecem que os termos democracia e liberdade não são sinônimos. E que democracia perfaz um conjunto de práticas e princípios que institucionalizam e, portanto, protegem a liberdade. Dentre esses princípios são relevantes, governo baseado em regras da maioria e o consentimento dos governados; existência de eleições livres e justas; proteção dos direitos das minorias; e respeito pelos direitos humanos básicos. 
Contudo, reforçam que os resultados da pesquisa indicam deterioração generalizada na prática da democracia nos últimos anos demonstrada pelo declínio nas liberdades da mídia e restrições à liberdade de expressão e designam esse cenário como uma recessão democrática manifesta pelo declínio da participação popular nas eleições e na política; pontos fracos no funcionamento do governo; declínio da confiança nas instituições; recurso cada vez menor dos principais partidos representativos; umento do fosso entre as elites políticas e os eleitorados; declínio das liberdades da mídia e erosão das liberdades civis, incluindo restrições à liberdade de expressão.

Um fenômeno interessante apontado no relatório é a oikofobia, aversão àquilo que é próximo, de si mesmo, em contraposição à xenofobia, sendo citado o livro de Edward Luce, The retreat of Western Liberalism (O recuo do liberalismo ocidental), no qual o autor defende a tese de que as elites se tornaram progressivamente mais céticas em relação à democracia desde a queda do Muro de Berlim:

Alguns culparam a ignorância popular e xenofobia pelos resultados do Brexit e da eleição de Trump argumentando que aqueles que votaram neles eram analfabetos políticos que foram enganados pela "política pós-verdade" ou pior, intolerantes com visões xenofóbicas. Desta forma, alguns opositores de Brexit e Trump apresentaram eleitores (e defensores de partidos populistas em geral) como a ameaça à democracia hoje. A reação popular a um sistema econômico e político que muitos eleitores sentem que os deixou para trás é apresentada como a causa das doenças da democracia, e não uma consequência deles (EIU, 2018, p.4).

O cientista político, filósofo brasileiro Wanderley Guilherme dos Santos, em entrevista concedida à Maria Cristina Fernandes, do Jornal Valor Econômico, em 29 de outubro deste ano, ressalta que

As democracias estão sendo corroídas pelas leis democráticas, depende como estas são aplicadas. Dependendo como se usa a lei essa nossa conversa aqui pode ser considerada um atentado contra a democracia. As instituições democráticas, pelas suas virtudes, de tolerância interpretativa, abrem um espaço para se governar autocraticamente em nome da democracia. (https://jornalggn.com.br/tag/blogs/wanderley-guilhermedos-santos, acesso 29 de outubro de 2018)

Steven Levitisky e Daniel Ziblatt cientistas políticos americanos e, docentes ena Universidade de Harvard, escreveram o livro, Como as Democracias Morrem, no qual analisam o fenômeno Trump e o comparam com exemplos históricos de ruptura democrática nos últimos 
cem anos, tais como a ascensão de Hitler e Mussolini (1930), as ditaduras militares na década de 70 na América Latina e a onda populista de extrema-direita na Europa.

Nesse contexto, os autores pontuam que os regimes democráticos não terminam, em pleno século XXI, com rupturas violentas (golpes militares ou revoluções), mas sim, com o autoritarismo que se instala a partir do enfraquecimento das instituições pilares da democracia, tais como o judiciário, a imprensa e pelo comprometimento contínuo das leis e normas explícitas ou implícitas (barreiras invisíveis) do jogo democrático.

Os autores citam como exemplos a Venezuela de Maduro e Chaves, a Rússia de Putin, o Peru de Fujimori, o Equador de Correa, ou seja, autocratas que usaram os meandros da democracia para torná-la uma ditadura velada. Esses autocratas têm perfil característico, figuras caricatas e com discurso enviesado, com viés populista.

Nesse cenário, as regras do jogo vão sendo alteradas paulatinamente e continuamente rompendo a teia das chamadas barreiras invisíveis, produzindo polarizações e, consequentemente, o predomínio de um grupo (de direita ou esquerda).

Os autores em determinado ponto do livro parecem descrever o atual cenário brasileiro das eleições para presidente, no qual os adversários são tratados como inimigos, a imprensa é acusada de divulgar mentiras e difamações, na qual a figura da liderança parece convocar para o bem-comum e uma causa prioritária, no nosso caso brasileiro, a segurança pública. Os pesquisadores acrescentam que lentamente, os autocratas minam as barreiras invisíveis e vão aprovando leis que os beneficiam, e, sobretudo, leis que silenciam a liberdade de expressão e a imprensa.

E assim, em determinado momento, o judiciário, a suprema corte está composta por legalistas conformados ao poder executivo. Assembleias constituintes podem ser convocadas realizando-se a aprovação de leis e regras que prevaleçam e assegurem o poder em exercício.

Cientista políticos brasileiros e filósofos tais como, Vladimir Safatle, Marilena Chaú, André Singer vêm pontuando a onda conservadora brasileira através de seminários e palestras em diferentes partes do Brasil. Safatle em seu livro, O circuito dos afetos, discorre sobre os vínculos sociais, a coesão social e propõe que em seu nível mais fundamental, as sociedades são circuitos de afetos e há uma adesão social construída através das afecções. Esse circuito permitirá compreender a natureza de comportamentos sociais e a incidência de regressões políticas. 
O autor aponta ainda que o medo é o afeto político central, pois sistemas políticos que se compreendem como fundamentados na institucionalização de liberdades individuais são indissociáveis da gestão e da produção social do medo (SAFATLE, 2016, p.17).

"A liberdade nas sociedades que inscrevem sujeitos sob a forma de indivíduos é indissociável da criação de uma cultura emergencial da segurança sempre latente, cultura do risco iminente e contínuo de ser violentado" (SAFATLE, 2016, p.18). Assim, o filósofo defende a tese de que só nos liberaremos de tais modos de determinação de sujeitos ao pensarmos a sociedade a partir de um circuito de afetos que não tenha o medo como fundamento, mas sim o desamparo como afeto político central. Ao longo do texto, o autor esclarece os mecanismos dos circuitos dos afetos que associam medo à alienação social e, desamparo à emancipação.

Ao analisar o processo democrático brasileiro Safatle aponta para uma redemocratização incompleta manifesta pela incapacidade de incorporar políticas populares:

(...) nossa redemocratização sempre incompleta, nossa transição infinita ruim em direção a uma democracia nunca vista produziu, ao final, um regime de cinismo e de guerra civil implícita. Assim, se estamos atualmente a discutir os fins da democracia em seu duplo sentido é porque poucos foram os países como o Brasil que se debateram de forma tão explícita contra sua impotência em dar forma institucional a uma soberania popular substantiva. Desde o final da ditadura, com sua campanha de Diretas Já, o Brasil se mostra como um país, como dizia Florestan Fernandes, da contrarrevolução permanente, da capacidade em gestar acordos de elite que afastem a possibilidade de verdadeiras incorporações políticas populares. (https://revistacult.uol.com.br/home/vladimir-safatle-os-fins-dademocracia/acesso 04 de novembro de 2018).

O estudo desenvolvido por Viscarra e Vasconcelos em 2016, corrobora a observação de Safatle, ao abordarem o crescimento da democracia procedimental mas sem uma cidadania cívica de apoio, sobretudo, nos países economicamente em desenvolvimento. E chamam a atenção para o fato da redemocratização brasileira instaurada em 1989 ser classificada como uma democracia de caráter institucional representativa, sem a incorporação da dimensão social, uma vez que aspectos associados à qualidade de vida das pessoas não foram atendidos. As autoras pontuam ainda que a qualidade da democracia brasileira deve ser problematizada, buscando-se compreender o afastamento das pessoas da esfera política a partir da insatisfação, descrença e baixa credibilidade nas instituições democráticas.

Nessa linha de raciocínio Viscarra e Vasconcelos desenvolveram a pesquisa intitulada, Democracia no brasil: a incidência da confiança institucional sobre a participação política dos 
brasileiros, tendo como matriz teórica a teoria culturalista ${ }^{7 \cdot}$ No decorrer do texto indicam que o sistema democrático adquire um sentido mais amplo ao incluir o cidadão como um agente responsável pela implementação da democracia no seu sentido mais pleno, e para tal são essenciais o aumento de confiança no regime institucional e a participação política das pessoas.

As autoras correlacionam a credibilidade dada ao sistema político ao engajamento da população nos âmbitos legais, o que por sua vez, aumentaria a estrutura democrática e a capacidade de gerenciamento de crises políticas e econômicas denotando o nível de amadurecimento e a qualidade das democracias.

Nesse ponto, as autoras referem-se à José Álvaro Moisés (2010 apud Viscarra e Vasconcelos, 2016, p.29) que aponta ser a desconfiança dos cidadãos fator gerador de ambivalência política, por influir na adesão das pessoas ao regime político. Para esse autor, a confiança implica em reciprocidade entre os envolvidos, levando à cooperação e à redução de riscos, entre as pessoas e essas e as instituições. Mas o panorama de desconfiança compromete a qualidade da democracia e indica que ela não está cumprindo o seu papel de formação de uma cultura política.

Importante destacar que o aprendizado político, a vivência e a experiência das pessoas sobre as instituições paulatinamente constrói valores e comportamentos cidadãos e, a credibilidade nas instituições, configurando-se assim, a cultura política e a solidez democrática. De acordo com Horton (1980, apud Viscarra e Vasconcelos, 2016, p.31), as atividades que a pessoa pratica constroem seu comportamento como cidadão, função importante tem a participação informal, pois é baseada na escolha individual, voluntária, e não associada à coerção ou obrigação.

Viscarra e Vasconcelos (2016, p. 30) ao citarem Baquero (2011) na discussão sobre a cultura política, destacam que

(...) a cultura política integra o indivíduo de duas formas: no plano interno, por meio de suas crenças e valores, e em sua perspectiva externa, mediante as atitudes e crenças dos cidadãos. Assim, é importante que haja, então, uma conexão da cultura política do lugar com sua perspectiva institucional, que não seja por imposição de fórmulas políticas, mas pela construção de aparatos políticos vindos do

\footnotetext{
${ }^{7}$ Tem como ponto central de análise o estudo do comportamento humano que considera os valores subjetivos dos indivíduos em relação a esfera política. A análise pela ciência política deve ser ampla, não se restringir ao estudo do governo. Vasconcelos e Viscarra, 2016, p.28.
} 
cidadão. Para Baquero (2011) a falta de confiança das pessoas na política no brasil influencia na pouca participação política dos cidadãos do país.

E as autoras avançam nessa reflexão indicando que a falta de cultura política no Brasil tem relação com o paternalismo, formalismo, personalismo, lealdade e patrimonialismo que são elementos que constituem a identidade nacional e denotam a cultura política marcada por traços de autoritarismo.

A participação política convencional ou informal é relevante pois transparece a tomada de decisões que os indivíduos tomam frente a um assunto, manifestando suas preferências. Por isso é essencial que sejam criados espaços de expressão social onde os cidadãos possam demandar melhor qualidade de vida e exercer a cidadania, tomando iniciativas e assumindo posicionamentos.

Ao avaliarem as variáveis escolaridade e participação política as pesquisadoras encontraram uma correlação positiva e robusta, indicando ser a escolaridade o fator mais influente sobre a participação política ${ }^{8}$. E verificou-se que quanto maior os anos de estudo, maior a chance de o cidadão atuar na participação política não convencional (participação em passeatas, boicotes, ocupação de instalações físicas, greves, abaixo-assinados, bloqueios, etc).

Vasconcelos e Viscarra (2016) constataram que a pesquisa desenvolvida corroborou os resultados de outros pesquisadores estudados por elas, Rifkin (1999) que afirma não existir democracia sem altos níveis de ensino, e Inglehart \& Welzel (2009) que apontaram o papel da escolarização na formação de valores democráticos.

Interessante observar que na pesquisa das autoras, a correlação classe social e participação política foi negativa indicando que a participação política não convencional depende muito mais do empoderamento dos cidadãos e da compreensão lógica da importância de participar, do que necessariamente ser dependente da reivindicação de uma classe social específica.

No que tange à participação política convencional (votar nas eleições, discutir política, fazer campanha, participar de partidos, etc) a idade interfere na participação política, pessoas em determinada faixa etária tendem a ser mais ativas politicamente. E, da mesma forma, a escolaridade determina o grau de envolvimento dos cidadãos na política. Já a classe social que na participação não convencional não teve correlação positiva, demonstrou ser uma variável de

\footnotetext{
${ }^{8}$ As pesquisadoras correlacionaram confiança nas instituições políticas, idade, escolaridade e classe social com a participação política convencional e não-convencional.
} 
implicação robusta na participação política convencional. Assim, perceber a própria condição social interfere na forma de apresentar e conduzir suas questões políticas.

Esses resultados permitem apontar fortes relações entre o desenvolvimento social e econômico de uma sociedade e o perfil democrático, seja pelo exercício da cidadania, pela expressão política, níveis de participação e pela confiança política dos indivíduos nas instituições. Remetendo-nos aos resultados do EIU (2017) é possível verificar que os países com democracias plenas (Austrália, Canadá, Dinamarca, Finlândia, Islândia, Irlanda, Luxemburgo, Nova Zelândia, Suécia e Estados Unidos) são aqueles com bons índices de desenvolvimento social, econômico e escolaridade (IDH, 2017 considerado muito alto).

\section{3 - CONSIDERAÇÕES FINAIS}

No transcorrer dos estudos realizados pode-se compreender que ao termo democracia estão associadas diferentes acepções, desde o exercício da participação eleitoral a partir do voto, até o pleno exercício de participação cidadã na tomada de decisões que perpassem a democracia política, econômica, social e cultural. Tornou-se clara a interelação entre as condições econômicas sociais, culturais e, sobretudo, educacionais que qualificam o exercício democrático em uma dada sociedade.

Ao conectarmos democracia e aspectos associados ao capitalismo e ao neoliberalismo visamos demonstrar o profundo entrelaçamento entre o modelo econômico de uma sociedade e a expressão democrática. E desvelar o quanto uma sociedade alicerçada no capital, no indivíduo/empresa, no efêmero e na percepção do presentismo pode vir a comprometer o exercício democrático. Contudo, essas conexões deverão ser melhor exploradas em outro ensaio, a partir do aprofundamento temático.

Quanto ao índice de democracia, as pesquisas apontaram para um encolhimento dos regimes democráticos, no que tange à liberdade de expressão e à cultura política. Fenômeno esse associado a uma onda conservadora que aflorou pela América e Europa.

No caso brasileiro, o índice democrático decaiu de 2016 para 2017, e o que vemos recentemente no Brasil é o aflorar do proto-fascismo em que as elites e a classe média postam-se claramente contra os pobres e as minorias e o renascimento do forte entrelaçamento entre Estado e a religião, associado ao aflorar de um nacionalismo anti-nacional, pois esvaziado de 
pluralismo e respeito à diversidade, e ameaças à democracia, à liberdade de expressão e às instituições democráticas.

As eleições brasileiras de 2018 para presidente apontaram um novo cenário político, o do esvaziamento da discussão política, dos debates nas TVs, o uso intensivo das redes sociais para divulgação de falsas notícias e o posicionamento do futuro presidente sobre pautas identitárias, tais como direitos das mulheres, indígenas, negros e LGBTs com discursos de ódio, segregação e estigmatização. O futuro presidente ocupou a cena política a partir de uma retórica preconceituosa e reacionária, roubando a cena com uma anticampanha que, anulou o espaço político de apresentação dos princípios e temáticas do novo governo.

Cientistas políticos e sociólogos definiram o conjunto de posicionamentos e ações do presidente eleito como uma estratégia arquitetada para retirar do campo político, o debate, a apresentação de propostas, o confronto de ideias e atribuíram essa estratégia a uma reação autoritária da direita que compreendeu ser o escondimento da agenda neoliberal a única maneira dela vir a ser implementada, visto a rejeição da sociedade brasileira a medidas neoliberais.

Ao avaliarmos a situação brasileira pode-se perceber uma atipicidade acerca dos ajustes neoliberais, visto o ensino superior ser gratuito (57 universidades federais), duas das maiores empresas do país serem públicas, 207 milhões de pessoas terem acesso ao sistema de saúde gratuito, $71 \%$ da população brasileira é contra as privatizações, $71 \%$ contra as reformas trabalhistas e $85 \%$ contra as reformas na previdência.

Nessa linha de raciocínio, Safatle analisa:

Desde o retorno das eleições diretas, o consórcio que promoveu o golpe de 1964 nunca havia conseguido comandar um processo eleitoral. Esteve sempre a reboque, aliado a outros projetos. Com a falência da Nova República, o esvaziamento da dicotomia PT-PSDB, esse consórcio (militares, empresariado, setores conservadores da Igreja e da mídia) enxergam a possibilidade de voltar ao poder sem intermediários (https://revistacult.uol.com.br/home/colunistas/vladimir-safatle/ - Os fins da democracia, acesso 4 de novembro de 2018, às 18h57).

A montagem da futura equipe de governo privilegia a presença de militares e de pessoas com perfil reacionário à problemática ambiental, cultural e social (pessoas vinculadas ao agronegócio defensoras da liberação massiva de agrotóxicos, avessas à preservação ambiental e proteção indígena, defensoras da flexibilização e liberação do licenciamento ambiental, críticas do ensino superior gratuito e do sistema do ENEM, contrárias às cotas raciais, defensoras do ensino 
privado, e adeptas da economia neoliberal em sues moldes mais amplos). Esse cenário configurase como conservador e marcado por retrocessos de décadas de conquistas sociais e socioambientais.

Retomando o livro, Circuito dos Afetos, pode-se propor que o medo foi o afeto mobilizador e central dessas eleições, medo de um governo de esquerda, medo da ascensão do autoritarismo e do fascismo, medo da retomada da ditadura militar, medo dos discursos de ódio e do preconceito, medo da violência urbana, medo da corrupção, medo da censura, medo da ruptura democrática. $\mathrm{O}$ medo como afeto central, ora escraviza e demanda uma figura de autoridade, ora limita a manifestação plena e a participação social.

A política pode ser lida como "mobilização de afetos que, por sua vez, expressam adesões a formas de vida distintas e conflituais, assim você não argumenta com afetos, você os descontitui” (SAFATLE, 2018). Nessa eleição vivenciamos o esvaziamento do cenário político e do espaço democrático de debates e participação social e, ao mesmo tempo, o reforço do medo como estratégia de alienação social.

Os brasileiros partidários de uma pauta afinada com o discurso da esquerda, por sua vez, vivenciaram o desamparo, pois, a franca ruptura da esquerda estava aclarada. Esse cenário exige a reunificação de uma pauta representativa da esquerda que faça resistência e oposição ao novo governo.

Nesse cenário, o desafio da maturidade democrática brasileira tornou-se significativo a partir de 2019, haja visto o perfil do presidente eleito e a inserção na câmara e senado de políticos alinhados ao conservadorismo religioso e militar.

A partir dos estudos pode-se constatar que a ampliação do processo democrático político passa pela modernização e democratização das relações sociais e do papel do Estado e que a democracia contemporânea se consolidará quando integrar as dimensões social, política e cultural. Nesse sentido, o desamparo como afeto emancipador poderá corroborar para que a democracia brasileira não seja rompida antes mesmo de alcançar a maturidade. 


\section{REFERÊNCIAS BIBLIOGRÁFICAS}

BAQUERO, M. A. Cultura Política na agenda da democratização na América Latina. In: BAQUERO, M. Culturas(s) Política(s) e democracia no século XXI na América Latina. Porto Alegre: UFRS Editora. 2011.

BOBBIO, N. O futuro das democracias: uma defesa das regras do jogo. 5.ed. Rio de Janeiro: Paz e terra. 1986. 171p.

Liberalismo e democracia. 4. Ed. São Paulo: Brasiliense. 1993. 100p.

BORDIEU, P. Léssence deu néolibeéralisme. Le Monde Diplomatique. Paris, mar. 1998, p.3

DARTOT, P. \& LAVAL, C. A nova razão do mundo: ensaio sobre a sociedade neoliberal. São Paulo: Boitempo, 2016.

FREEDOM HOUSE. Freedom in the world. 2013.

FREITAS, V. O código social da obsolescência: um estudo de A sociedade de consumo, de Jean Baudrillard. In: PIMENTA, Solange M.; CORREAA, Maria C. e VELOSO, H. M. (Org.). Sociedade e consumo: múltiplas dimensões na contemporaneidade. Curitiba: Juruá, 2010, p. 79-94.

HARTOG, F. Regimes de historicidade: presentismo e experiências do tempo. Belo Horizonte: Autêntica, 2015.

INGLEHART, R. \& WELZEL, C. Modernização, mudança cultural e democracia. São Paulo: Verbena, 2009.

JORNAL VALOR ECONÔMICO. 29 de outubro de 2018. (https://jornalggn.com.br/tag/blogs/wanderley-guilherme-dos-santos, acesso 29 de outubro de 2018)

KAYSER, E. Democracia, liberdade e utopias. Anais [do] 14 Encontro Estadual de História da ANPUH-RS, Porto Alegre, 24 a 27 de julho de 2018 [e-book]. / Organizadores: Paulo Roberto Staudt Moreira; Everton Reis Quevedo; José Edimar de Souza; Marcelo Vianna; Rodrigo Luis dos Santos. -- Porto Alegre: ANPUH-RS, 2018.

148 trabalhos completos. http://www.eeh2018.anpuh-rs.org.br/site/anaiscomplementares

LEVITSKY, S. \& ZIBLETT, D. Como as democracias morrem. Rio de Janeiro: Editora Zahar, 2018. 280p.

LIPOVETSKY, GILLES. A Era do Vazio: ensaios sobre o individualismo contemporâneo. Tradução de Therezinha Monteiro Deutsch. São Paulo: Editora Manole, 2005, 224 p.

LUCE, E. The retreat of Western liberalism, Little, Brown. 2017.

MOISÉS, A. D. Democracia e confiança: por que os cidadãos desconfiam das instituições públicas? São Paulo: Editora USP. 2010.

NETO, A. C. Democracia: velhas e novas controvérsias. Estudo de Psicologia Universidade Federal do Rio Grande do Norte: Natal. 2(2), 1997, 287-312p. 
OLIVEIRA, F. de. A sociologia política e a democracia no Brasil. Política \& Sociedade. Universidade Federal de Santa Catarina: Florianópolis. v.2, n.3, 2003. 27-43p. https://periodicos.ufsc.br/index.php/politica/article/view/2016

PNUD. Relatório Nacional de Desenvolvimento Humano. ONU. 2017.

PITF. Polity IV Project: 2010. Universidade de Maryland. 2014.

ROUSSEAU, J. J. DO CONTRATO SOCIAL. In: Os pensadores (3 ed., pp. 15-145). São Paulo: Abril Cultural. 1983.

SAFATLE, V. O circuito dos afetos: corpos políticos, desamparo e o fim do indivíduo. 2 ed. Ver.; 2. reimp. Belo Horizonte: Autêntica Editora, 2016. 358p.

Os fins da democracia. https://revistacult.uol.com.br/home/colunistas/vladimirsafatle/, acesso 4 de novembro de 2018, às $18 \mathrm{~h} 57$.

THE ECONOMIST. Democracy Index 2013. The Economist Intelligence Unit.2013.

THE ECONOMIST. Democracy Index 2017: free speech under attack. The Economist Intelligence Unit. Retrieved 31 January 2018.

THERBORN, G. A crise e o futuro do capitalismo. In: SADER, Emir. GENTILI, P. (Org.). Pós-neolibralismo: as políticas sociais e o Estado Democrático. São Paulo: Paz e Terra, 1995.

VASCONCELOS, C. \& CISCARRA, S. P. Democracia no Brasil: a incidência da confiança institucioinal sobre a participação política dos brasileiros. Caderno Eletrônico de Ciências Sociais, Vitória, v.4, n.1, 24-44p.

ZIZEK, S. Primeiro como tragédia depois como farsa. Tradução Maria Beatriz Medina. São Paulo: Boitempo, 2011. 272p. 